\title{
PELVIC TUMOUR - AN UNUSUAL CAUSE OF HEMOLYSIS
}

Banashree Das ${ }^{1}$, Juhi Bharti²

\section{HOW TO CITE THIS ARTICLE:}

Banashree Das, Juhi Bharti. "Pelvic tumour - an unusual cause of hemolysis". Journal of Evolution of Medical and Dental Sciences 2013; Vol2, Issue 29, July 22; Page: 5407-5410.

BACKGROUND: Dermoid tumour accounts for more than 20 percent of all ovarian neoplasm. Dermoid tumour associated with autoimmune hemolytic anaemia is very rare. We report a rare case of hemolysis due to pelvic tumour. CASE REPORT: Patient presented with complaints of pain abdomen, breathlessness, mild jaundice and fever for 1 month with ultrasound report showing complex ovarian mass, mainly cystic, making a diagnosis of ovarian tumour. Her initial hemoglobin was 2.5 gram percent. On further workup, she was diagnosed to have autoimmune hemolytic anemia. Abdominal computed tomography revealed large presacral cystic mass with fat component. Exploratory laparotomy and resection of tumour was done. On histopathologic examination, cyst was confirmed to be dermoid cyst. CONCLUSION: Though presacral dermoid cyst is rare in adults and its association with autoimmune hemolysis is even rarer, but if dermoid is coexisting with anaemia, we must always think of an autoimmune cause.

KEYWORDS: Dermoid tumour, autoimmune hemolysis, anaemia, presacral mass, ovarian tumour. MESH TERMS: Dermoid cyst, autoimmune hemolytic anemia.

INTRODUCTION: Dermoid tumours are germ cell tumours that can arise anywhere in the body, out of which ovarian is the most common site of origin in a female of reproductive age group. It accounts for more than $20 \%$ of all ovarian neoplasms ${ }^{1}$. They are usually asymptomatic and diagnosed incidentally. Sometimes, ovarian dermoid can present with complications like, torsion (16\% of ovarian teratomas), rupture (1-4\%), malignant transformation (1- 2\%), infection (1\%) and autoimmune hemolytic anaemia $(<1 \%)$ 2, 3, 4. Dermoid tumor associated with autoimmune hemolytic anaemia (AIHA) is very rare, though there are cases reported in literature. However, all females with pain abdomen with pelvic masses need not always have ovarian cause as the etiology, presacral dermoid may be present, although it is rare in adults.

Here is a rare unsuspected case of presacral dermoid cyst in an adult female causing secondary autoimmune hemolytic anaemia with thrombocytopenia.

CASE REPORT: A 28 years female attended gynecology emergency with complaints of pain abdomen, generalised weakness, breathlessness, jaundice and off and on fever for one month. She was referred from outside in view of ovarian tumor along with an ultrasound pelvic scan showing complex ovarian mass, mainly cystic. At the time of admission, patient was dyspneic with severe pallor and mild jaundice. On per abdominal examination, there was an abdominopelvic mass corresponding to 12-14 weeks gravid uterus and hepatosplenomegaly. On pelvic and digital rectal examination, uterus was of normal size. There was a pelvic mass, most probably arising from adnexa and extending upto rectovaginal septum, making a provisional diagnosis of ovarian tumour with very severe anaemia.

Her initial investigation reports showed hemoglobin(Hb) $2.5 \mathrm{~g} \%$, platelet count 75000 cells/cu mm, serum bilirubin $2.7 \mathrm{mg} / \mathrm{dl}$ (Direct-0.8, indirerct-1.9), reticulocyte count- $34.6 \%$ and 
haematocrit- 22\%. Peripheral smear revealed a picture of severe dimorphic anaemia with thrombocytopenia, tear drop cells \& target cells. She was further worked up to find the cause of anaemia which showed serum lactate dehydrogenase (S. LDH)-1737 U/L, direct and indirect Coombs test positive, hemoglobin in urine - $0.88 \mathrm{~g} / \mathrm{dl}$, Glucose 6-Phosphate dehydrogenase (G6PD)not deficient, osmotic fragility-within normal limits, serum.vitamin $\mathrm{B}_{12}$ was $234 \mathrm{pg} / \mathrm{ml}$ (180-934 $\mathrm{pg} / \mathrm{ml}$ ), serum folate was $5.62 \mathrm{ng} / \mathrm{ml}$. In the mean time, she was managed with packed cells and platelet transfusions. Her provisional diagnosis was changed to ovarian tumour with autoimmune hemolytic anaemia and thrombocytopenia. She was started on methyl prednisolone $1.5 \mathrm{mg} / \mathrm{kg}$ body weight/day). However, she required blood transfusions to maintain her $\mathrm{Hb}$ level. Her abdominal computed tomography (CT) report showed large pre sacral cystic mass with fat component measuring 10x11x12 cm suggestive of pre sacral dermoid cyst (Figure 1).

She was then planned for exploratory laparotomy and resection of tumour. On laparotomy, uterus, bilateral tubes and ovaries were found to be normal. Pre sacral cyst of roughly $10 \times 12 \mathrm{~cm}$, densely adherent to sacrum, coccyx \& vaginal wall $(10 \times 12 \mathrm{~cm})$ was present which was resected. During dissection, lower rectum got injured due to adhesions, primary repair of rectum with loop sigmoid colostomy was done. On gross examination, it was a well encapsulated mass, cystic, multiloculated, containing greasy material, teeth \& hair. Histopathologically, cyst wall was lined by stratified squamous epithelium with skin appendage, thus confirmed to be dermoid cyst (Figure 2).

Post operatively, patient responded well to tapering doses of methylprednisolone with steady rise in hemoglobin \& platelet count. Indirect Coombs test was negative about 1 month after surgery. MRI Pelvis (done after 5 months of surgery) showed no evidence of residual mass. There was mild free fluid in pelvis with associated pelvic inflammation. Now the patient is doing well without steroids for last one year of follow up.

DISCUSSION: Though there are reports of ovarian dermoid tumour causing autoimmune hemolytic anemia, any literature related to pre sacral dermoid associated with secondary autoimmune hemolytic anemia could not be found. Pre sacral masses are diagnosed mainly in infancy and childhood. It is very rare in adults. Cases of pre sacral dermoid in adults have been reported but this case is unique as it had an unusual presentation in the form of autoimmune hemolysis. The early identification of this rare association is important as resection of the tumor offers cure for anaemia. Therefore, anaemia associated with dermoid should always be investigated to exclude an autoimmune cause. The mechanism of hemolysis in dermoid is not well defined. There are several hypotheses such as cross reactivity of tumor \& red blood cell (RBC) antigens, tumor may form RBC auto-antibodies or alteration of RBC molecules by the tumor, rendering them antigenic to the host 5 .

The presence of severe anaemia with jaundice and hepatosplenomegaly along with positive direct and indirect Coombs test led to the diagnosis of autoimmune hemolytic anaemia in this case which prompted us to use prednisolone in this case. Since the patient did not show adequate response to steroids, transfusions were done for symptomatic improvement of the patient and build up hemoglobin and platelets to desirable levels so as to withstand the trauma of surgery. After surgical resection of the tumor, there was a dramatic improvement both clinically and in laboratory parameters.

Thus we see that removal of the tumor is the only effective treatment in such cases. Though presacral dermoid cyst is rare in adults and its association with autoimmune hemolysis is even 
rarer, but if dermoid is coexisting with anemia, we must always think of an autoimmune cause. Also, the gynaecologists must keep in mind that pelvic tumours are not always ovarian or uterine in origin.

\section{REFERENCES:}

1. Hasanzadeh M, Tabare S, Mirzaen S. Ovarian dermoid cyst. Professional Med J 2010; 17 (3): 512-515.

2. Comerci JT Jr, Licciardi F, Bergh PA, Gregori C, Breen JL. Mature cystic teratoma: a clinicopathologic evaluation of 517 cases and review of the literature. Obstet Gynecol 1994; 84:22-28.

3. Outwater EK, Siegelman ES, Hunt JL. Ovarian teratomas: tumor types and imaging characteristics. RadioGraphics 2001; 21:475-490.

4. Kido A, Togashi K, Konishi I, Kataoka M L, Koyama T, Ueda H, Fujii S, Konishi J Dermoid cysts of the ovary with malignant transformation: MR appearance. American Journal of Roentgenology 1999; 172: 445-449.

5. Cobo F, Pereira A, Nomdedeu B, Gallart T, Ordi J, Torne A, Monserrat E, Rozman C. Ovarian dermoid cyst-associated autoimmune hemolytic anemia: a case report with emphasis on pathogenic mechanisms. Am J Clin Pathol 1996; 105: 567-71.

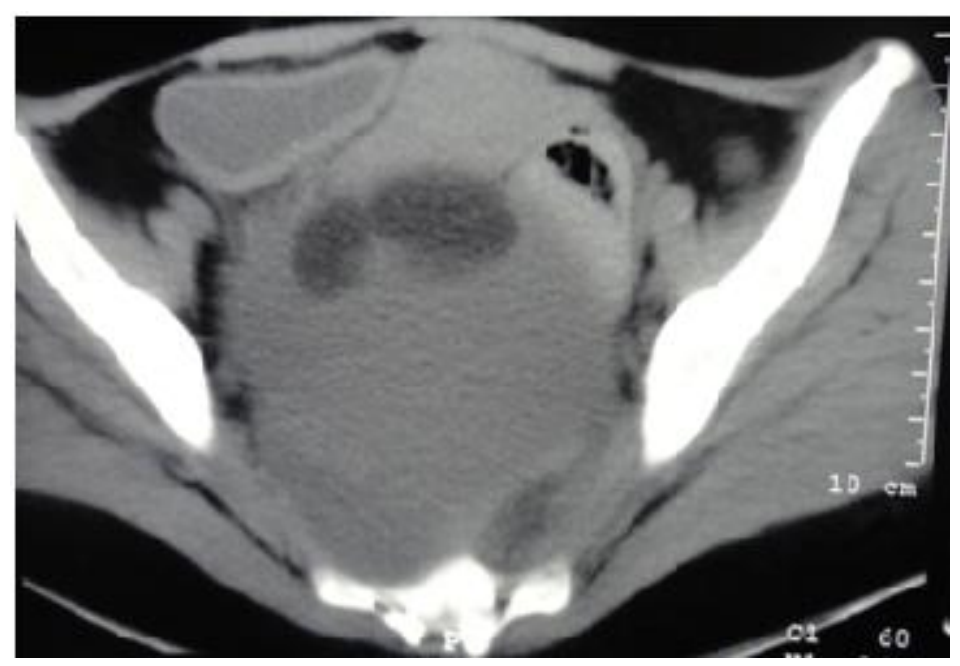

Figure 1: Computed tomography showing presacral cystic mass with fat component 


\section{CASE REPORT}

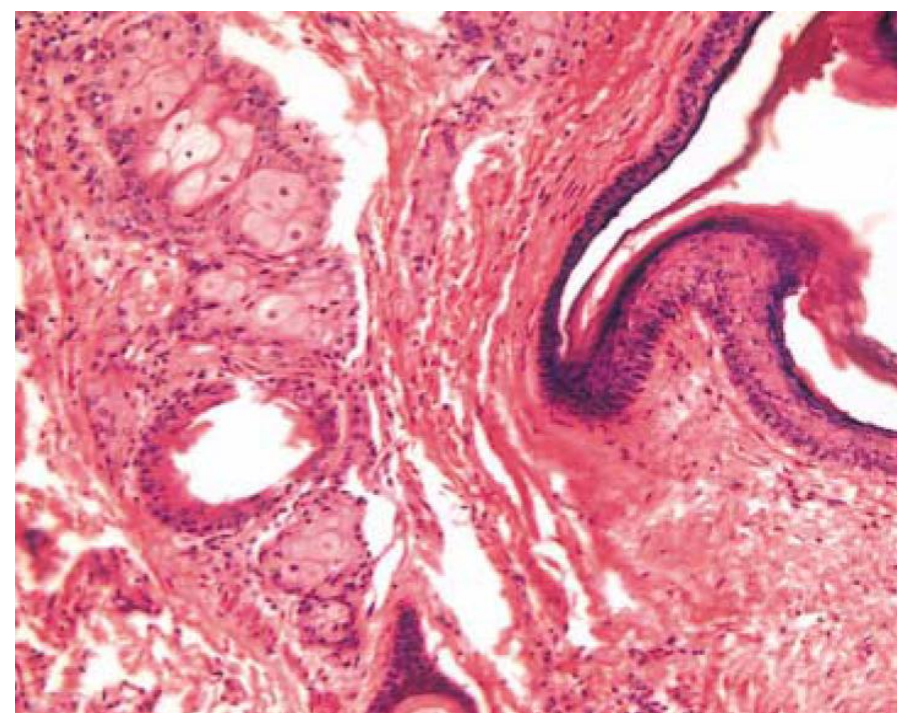

Figure 2: Cyst wall lined by stratified squamous epithelium with skin appendages

\section{AUTHORS:}

1. Banashree Das

2. Juhi Bharti

\section{PARTICULARS OF CONTRIBUTORS:}

1. Professor, Department of Obstetrics and Gynaecology, Vardhman Mahavir Medical College and Safdarjung Hospital, New Delhi, India

2. Senior Resident, Department of Obstetrics and Gynaecology, Vardhman Mahavir Medical College and Safdarjung Hospital, New Delhi, India

\section{NAME ADRRESS EMAIL ID OF THE} CORRESPONDING AUTHOR:

Dr. Banashree Das,

House No. 2, Sadhana Enclave, New Delhi - 110017, India.

Email: banashree_a@yahoo.com

Date of Submission: 12/07/2013.

Date of Peer Review: 13/07/2013.

Date of Acceptance: 16/07/2013.

Date of Publishing: 19/07/2013 